\title{
Transformative Learning: Advocating for a Holistic Approach
}

\author{
Adamantios Papastamatis ${ }^{1} \&$ Eugenia A. Panitsides ${ }^{1}$ \\ ${ }^{1}$ Department of Educationaland Social Policy, University of Macedonia, Thessaloniki, Greece \\ Correspondence: Eugenia A. Panitsides, Department of Educational and Social Policy, University of Macedonia, \\ 156 Egnatia str, Thessaloniki, 54006, Greece. Tel: 30-69-3736-7476. E-mail: epantsidou@uom.gr
}

\author{
Received: September 11, 2014 Accepted: October 6, 2014 Online Published: November 15, 2014 \\ doi:10.5539/res.v6n4p74 \\ URL: http://dx.doi.org/10.5539/res.v6n4p74
}

\begin{abstract}
The present study lays the foundations for an integrated theory of transformative learning. Traditionally, theory and research in adult education have examined learning as a purely cognitive process. However, recent studies have shifted emphasis onto more holistic approaches, perceiving the individual as a whole, consisting of mind, body and spirit. Through thorough review of relevant studies, the present paper seeks to point out that transformative theories of learning have traditionally over-relied on rational and cognitive processes in describing perspective transformation, while it makes the assumption that for transformative learning to take place, cognitive, physical, emotional, and spiritual dimensions are closely interrelated. When we come to knowing and learning, linear and fragmented approaches cannot account for the perplexity of the human being, consisting of mind, body and spirit, and therefore all these parameters should be attended to.
\end{abstract}

Keywords: transformative learning, adult learning, holistic learning, perspective transformation

\section{Introduction}

Adult education and learning are inherently intertwined with change, change in knowledge, understanding, attitudes, beliefs, skills and/or behaviors. Traditionally, theory and research in adult education have examined learning as a purely cognitive process, drawing on rationality and cognitivism, such as in experiential learning (Kolb, 1984), critical thinking (Brookfield, 1989), reflective practice (Schön, 1983) and transformative learning (Freire, 1972; Mezirow, 1991).

At the heart of the foregoing conceptual frameworks of adult education and learning, there is found centrality of experience, along with transformative learning, perceiving learning in adulthood as a means of personal and social transformation. It is practically assumed that adults have the ability to reflect critically on their assumptions. As a result, adult learning constitutes a transformative rather than an assimilating process (Freire, 1972; Mezirow, 1991). As posited by Mezirow (2005), instead of focusing on the adult learner as andragogy and, to a large extent, self-directing learning theories have done, transformative learning evolves around the cognitive process of meaning making. Hence, it constitutes a dynamic interpretative framework for contextualizing adult learning as a powerful lever of transformation.

Furthermore, transformative learning forms predominately an adult learning theory, as it is grounded on adult accumulative experience and a higher level of cognitive functioning than that reached in childhood. In effect, it constitutes a mode of resolving contradictions in a dialectical fashion. In this respect, mediated by raising awareness of novel possibilities and perspectives, it thereby becomes a process of moving towards more complex ways of viewing ourselves and where we stand, potentially leading to raising personal responsibility for the societies we live in (Taylor, Marienau \& Fiddlen, 2000).

In the essence of transformative learning theory, there is found the assumption that a sudden or dramatic event may induce changes in individuals, in ways that both themselves and others can recognize. Indeed, having emerged in the context of adult learning theory, it moves away from traditional educational practices of rigid memorization, analytically describing processes that challenge current knowledge frames (Adamson \& Bailie, 2012). It is grounded on constructivist - developmental approaches, drawing on rationality and cognitive processes as a means of effective perspective transformation, such as in Habermas' (1970), Kohlberg's (1981), Loevinger's (1976), Piaget's (1954) and Riegel's (1973) works. In this context, influential transformative learning theories have been proposed by Freire (1972), Kolb (1984), and more recently by Mezirow (1991).

However, recent studies, such as by Clark (2005), Dirkx (2001), Dixon and Baltes (1996), Heshusious and 
Ballard (1996), Meyer (2012), Michelon (1998), and Mulvihill (2003), have shifted emphasis towards more holistic approaches, perceiving the individual as a whole, consisting of mind, body and spirit. In this regard, in the present study we argue that in order a holistic transformation to take place, it requires the involvement of the whole person, that is, addressing all mind, body and spirit. Hence, through thorough review of relevant studies, the present paper seeks to point out that transformative theories of learning have traditionally over-relied on rational and cognitive processes in describing perspective transformation, while it presumes that for effective transformative learning to take place, cognitive, physical, emotional, and spiritual dimensions are closely interrelated.

\section{Method}

Literature review was conducted following a four-stage process, including research of preliminary sources, use of secondary sources, study of primary sources and synthesis of the literature (Gall, Borg \& Gall, 1996, p. 117). Preliminary source research was conducted using bibliographic databases, such as Scopus database, Educational Resources Information Center (ERIC) and Hellenic Academic Libraries Link (HEAL LINK). References within preliminary sources helped draw up a comprehensive list of primary material relevant to the topic, which once assembled and studied through a critical approach, allowed a deeper insight in the subject and a broader understanding.

\section{A review of Transformative Learning Theories}

\subsection{Freire's Social-Emancipatory Theories of Transformative Learning}

Paulo Freire's theory of transformative learning is a socio-cultural approach to transformative learning. According to Freire (1972) personal empowerment and social transformations are two inseparable processes. Getting emancipated from false consciousness requires political action aimed at changing the world. Paulo Freire worked with indigenous adults in his home-country, Brazil, helping them to gain literacy skills through the process of "conscientization", namely an ongoing process wherein the individuals become increasingly aware of the social and political conditions under which they lead, becoming eventually agents of social change.

The conscientization framework is ultimately what enables individuals undergoing the "awakening" experience to engage in an authentic dialectical process, starting with contemplating on their pre-constructed biases, concepts and assumptions, and gradually moving on to identifying interconnections and broader meaning of the world they live in.

\subsection{Kolb's Model of Experiential Learning}

David Kolb, being the theorist most closely associated with experiential learning (Kolb, 1984), proposed a model on the underlying structure of experiential learning as an ongoing process of experiencing and adaptation to the world rather than a mere series of outcomes. He came up with a cyclical four-stage model to conceptualize this process (concrete experience, reflective observation, abstract conceptualization and the active experimentation). The cycle begins with the learner being involved in a concrete experience, going on with reflecting on this experience and attributing meaning to it. Then, the learner integrates the meaning drawn from this particular experience into the established network of previous experiences to formulate abstract concepts and reach conclusions, which finally lead to new concrete experiences.

It is evident that Kolb's cycle accounts for the way learners can make out abstract generalizations from concrete experiences and develop concepts for future experimentation, based on their reflection. Hence, experiential learning is often defined as learning by doing, however, it actually refers to learning as a result of reflection on doing (Hillier, 2005).

\subsection{Mezirow's Psycho-Critical Model of Transformative Learning}

Jack Mezirow is regarded as the "father" of transformative learning, despite the fact that he has acknowledged his being influenced by Paulo Freire. However, while Freire (1972) emphasized the need for transformative learning at the social level, Mezirow's theory $(1991,2000)$ concentrates primarily on the process of personal transformation and empowerment. Precisely, he argues that transformative learning is a form of learning through which previously uncritically assimilated beliefs, attitudes, assumptions and emotional reactions are questioned and thereby become more explicit and thoroughly validated.

Mezirow believes that transformations involve both changes in meaning schemes and changes in meaning perspectives of reference frames. A meaning scheme is a specific set of beliefs, biases, feelings, attitudes and knowledge, while a frame of reference offers an integrated set of meaning schemes, assumptions and expectations through which individuals filter their experiences. Mezirow (1991) additionally suggests that 
reflection has three main purposes to serve: to guide action, to add coherence to the unfamiliar and to reassess the justifications of what already known. The last one is pivotal to critical reflection and works towards re-examining and potentially transforming the structure of assumptions through which a learner makes meaning. Mezirow goes on to say that assumptions are in effect structured through socialization processes, pointing out that in adulthood individuals reassess the assumptions they acquired during childhood, often in response to disorienting dilemmas that challenge their perspective and their frame of reference for interpreting reality. In this regard, he suggests that the transformational process unravels in ten consecutive stages:

1) a disorienting dilemma,

2) self-examination with feelings of fear, anger, guilt or shame,

3) a critical evaluation of assumptions

4) recognition that one's discontent and the process of transformation are shared

5) exploration of options for new roles, relationships and actions

6) formulating a course of action

7) acquiring knowledge and skills for implementing one's plans

8) provisional trying of new roles

9) building competence and self-confidence in new roles and relationships

10) reintegration into one's life on the basis of conditions dictated by one's new perspective.

(Mezirow, 2000, p.22)

\section{Towards a Holistic Approach of Transformative Learning}

As pointed out in the beginning of this work, all the above theories of transformative learning are based on cognitive function. In other words, arguments are weighted, evidence is evaluated and conclusions are drawn.

Since the 1990s transformative learning has been a central theme in adult education. Almost every year transformative learning conferences take place both in national and international settings. However, there has been a growing number of theorists who argue that the various models of transformative learning over-rely on rationality and cognitive processes as the means of effective perspective transformation. It is practically assumed that rational thinking is basically a Western concept, since researchers in the West tend to ignore the body, emotions, and spirit as valid learning agents, limiting thus learning to a sheer cognitive process that takes place in the mind. This emphasis on the mind emanates from Descartes' wide influence in Western science and philosophy, denoting "I think, therefore I am", separating thereby the mind from the body. The segregation between mind and body has been further reinforced by the Enlightment philosophers, who largely argued that knowledge could be obtained only through reason (Merriam, Caffarella \& Baumgartner, 2007). This has led to the Cartesian dualism, the mind/body split, which privileges reason and delegitimizes the body as a mode of knowing (Bordo, 1987).

In this context, Meyer (2012) suggested two further reasons accounting for the emphasis on cognitive processes. The first reason is rooted in childhood, since most individuals have been socialized to assume play and work as being incompatible. The second one is grounded on the operational aim of the workplace, as it mainly concerns the outcomes, that is, the products of the services provided and not the opportunities created for holistic learning and development. Hence, physical and affective learning have been suspended under the hegemony of "objectivity", being predominately regarded as biased and undesirable, while considered useful for our intimate lives but not for claiming knowledge about the world (Heshusious \& Ballard, 1996).

\subsection{The Body}

As mentioned above, although human beings are practically the interface of mind, body and spirit, physical, emotional and spiritual dimensions have rarely been taken into account in debates on learning and knowing. Yet, most individuals can recall a time when understanding was reached while in the process of doing something. Likewise, most of us are acquainted with the ancient Chinese saying "what I hear I forget, what I see I remember, what I do I understand". In learning therefore, both the learning outcomes and the action taken are synonymous (Howden, 2012). This approach to learning has been originated in the West by Dewey (1938), who stressed that we actually "learn by doing". Learning by doing is a holistic experience in which the whole person is engaged and on which learning is grounded, making it evident that ways of learning and knowing beyond the cognitive domain are equally important. 
In this regard, in an interesting work by Michelon (1998), it is advocated that the concept of experiential learning is directly linked to the concept of "thinking with the body". In the same vein, the notion of tacit knowledge proposed by Polanyi (1969) implies that knowledge begins in the body. Tacit knowledge actually refers to the fact that people are able to possess knowledge even though this knowledge cannot be worded, while it involves the ability to formulate and solve problems within complicated and unstructured settings (Dixon \& Balters 1996; Polanyi, 1969). As Polanyi (1969, pp. 147-148) has elegantly put it forward:

"Every time we make sense of the world, we rely on our tacit knowledge, of impacts made by the world on our body and the complex responses of our body to these impacts. Such is the exceptional position of our body in the universe".

Mathews (1998, p. 27) has also referred to physical learning as "the embodied experience of being and doing" overtly expressed "at the heart of the arts and applied culture". He recalls his early schooling when he was obliged to sit still and "endure", rather than be actively engaged in learning. The only exception was his fifth-grade teacher who acknowledged the importance of physical action in learning, constantly formulating rituals. For instance, she would provide white lab coats for pupils to wear, explaining that when pupils put on the coats they could be intriguingly transformed into scientists.

According to Clark (2005, pp. 211-212), the reemergence of the body as a source of knowledge is due to various reasons. The first one is related to the feminist movement, as, inter alia, the cause for which women had been marginalized in Western culture, has been highly concerned with the body. Consciousness-raising groups served as a source of physical learning as women examined how patriarchy oppressed them through the regulation of the body. What has been considered secret and shameful began to be the object of study and public exposure. This approach has been extensively developed by feminists, who perceive the body as the foundation for women's conceptualization of the self and the construction of knowledge. The second reason for re-establishing the body as a locus of learning is associated with our everyday experience. In effect, everybody has been involved in stressful situations, while most of us have had the disconcerting experience of stress manifesting itself in our bodies far before our brains manage to figure out what exactly the trouble is. Finally, the third reason is related to the fact that the body as a site of learning provides actually a more authentic conceptualization for the individual.

\subsection{The Emotions}

Closely aligned to physical learning is affective learning. Nowadays, it is widely acknowledged that due to the fact that receptors are located throughout the human body, emotions can be stored and mediated by parts of our bodies other than the brain (Merriam, 2005). In an interesting work, Dirkx (2001) challenges the cognitively based concept of transformative learning as being limited in scope. Dirkx (2001) assumes that learning itself is inherently an imaginative, emotional act and that significant learning is impossible without emotion. Actually, he impies that imagination must be nurtured with its own kind of nourishment, while it is through emotions that deeply personal meaningful connections are made so that learning can effectively take place.

Along the same lines, Taylor (2000) states that transformative learning has granted too much importance on critical reflection and underestimated the role of emotions and feelings in the process of transformation. Moreover, he argues that several studies have indicated that people's emotions must be worked through before they can engage in critical reflection. In the same vein, Mulvihill (2003) emphasizes the importance that the affective domain plays in transformative learning experiences as depicted in his study with survivors of clergy abuse. He posits that when learners are encouraged to uncover the emotional impact of their perspectives and meanings and to integrate the new information through alternative learning channels, a holistic transformative model has to be embraced. In effect, Kramer (2000) argues, most emotional existential dilemmas in life do not tend to be resolved through the linear model proposed by Mezirow (1991), stressing that such dilemmas require alternative modes of representation, such as art, metaphor and non linear logic.

Furthermore, research on transformative learning has confirmed the essential role of relationships (Taylor, 2000). In other words, for effective transformation to take place, in addition to rational discourses, relational discourses are indispensable, as well. It is common place nowadays that transformative learning is an interdependent process built on trust and involvement of other individuals, rather than an independent act. In this respect, Glaser (1988) argues that almost all learning issues are associated with relationships, as other individuals exert direct influence over one's own thinking and behavior, once again stressing that learning is as much affective as it is cognitive.

It has also been largely argued that there is a direct link between holistic learning and engaging in collective action. Overruling the individualistic focus of the Mezirowan approach, many theorists have drawn on the social 
context of education and learning, with social change or the transformation undergone by groups and organizations, as the ultimate goal (Lipson \& Cranton, 2009). Relevant studies (Merriam \& Ntseane, 2008; Nitschke \& Malvicini, 2013; Yorks \& Marsick, 2000) have indicated that through combining rational learning with affective, intuitive, and spiritual ways of knowing, individuals may develop a critical awareness, whereby contributing to the transformation of both their lives and the communities they live in (Shor, 1992). Precisely, research findings have depicted that holistic approaches in transformative learning can foster meaning making, empowerment, and the emergence of self-managing groups (Nitschke \& Malvicini, 2013), helping learners develop a critical engagement with their organizational and social world, increasingly recognizing that the existing state of affairs does not exhaust all possibilities and arriving at alternative courses of action. (Yorks \& Marsick, 2000)

\subsection{The Spirit}

Moreover, in their study in the context of an African nation, Merriam and Ntseane (2008) have noticed that some of the events that triggered the transformational learning process were seen as being caused by forces beyond the natural world, set within individuals' spiritual system. It was therefore presumed that one's cultural context may shape transformational learning, as cultural values largely determine the choice of assumptions to examine and the new perspectives and subsequent behaviors to engage in.

Hence, alike physical and emotional learning, spiritual learning has also to do with meaning-making (Merriam, Caffarella \& Boumgartner, 2007). Spirituality revolves around personal beliefs and experience of a divine spirit or higher purpose, determining how we construct meaning, and what we individually and collectively experience and attend to and honor as the "sacred" in our lives (Tisdell, 2003, p. 29). Some similar words are grace, heart, flow, life force, and soul (Merriam, Caffarellla \& Baumgartner, 2007). As Kidd (1973) eloquently points out, spiritual learning involves the celebration, the affirmation, the enlargement of full consciousness and the search for that part of the individual that is really human. Likewise, Boyd $(1989,1991)$ argues that transformation is an inner journey of individualization from parts of the psyche such as the ego and the collective unconscious, a process actually of knowing through reflection on the psychic structures.

\subsection{Practical Implications}

Although most educators believe that we are corporal and thinking beings, their image of the adults as learners pertains to being "merely an animal to be socialized, a computer to be programmed, a unit of production to be harnessed and utilized, a consumer to be won" (Sloan, 2005, p. 27). Formal programs in fact suffer from order, hierarchies, grades, tests, a gloried past, control, deprivation, remoteness of various kinds, and weighty seriousness (Moore, 2005).

In this regard, several studies have advocated for the need of a holistic pedagogy, demonstrating that effective learning rests on holistic development, in which all developmental measures, intellectual, social, emotional, moral and spiritual, are attended to (Dencev \& Collister, 2010; Lawrence \& Cranton, 2009; Lovat et al., 2010; Pugh, 2011; Wang \& Yorks, 2012). To this end, Taggart (2001, p. 328) points out, "holistic educators often draw upon the visual arts, dance, movement and drama to help learners see themselves as embodied forms of intelligence in action rather than disembodied centers of disinterested reason". In effect, Wang and Yorks (2012) presume that the use of holistic educational approaches can take place even in classes traditionally defined as being highly instrumental and practical. Their findings indicated both affective and cognitive changes to have stemmed from engagement in holistic activities, inducing conscious awareness of how meaning schemes shape one's actions, while making learners' subjective self-perceptions objective and accessible for self-reflection. Along the same lines, Pugh (2011) argues that the active and continued engagement with particular content involved in a holistic experience, ensures that individuals undergoing transformative experiences will develop deeper and more enduring understandings of that content. Furthermore, a holistic classroom context, fostering authentic ways of knowing and being, may enable students to experience profound paradigm shifts, transforming both their personal and professional practice (Dencev \& Collister, 2010).

Thus, taking in account that, according to Mezirow (1991), one of the most important learning tasks in adulthood, is making meaning, we think that to the extent that physical, affective and spiritual domains are concerned with meaning- making, they can be considered equally useful in providing a convincing rationale for interpreting adult learning. However, relevant research is rather limited in this field, calling for further investigation.

\section{Conclusions}

The present paper has attempted, through a thorough literature review, to lay the foundations for an integrated theory of transformative learning. Traditionally, theory and research in adult education have examined learning 
as a purely cognitive process. In this context, transformative learning theories have become a dynamic interpretative framework for contextualizing learning as a powerful lever of transformation, primarily associated with adult learning, as resting on a higher level of cognitive functioning.

However, the constructive-developmental approach to transformative learning stemming from sheer cognitive orientation, has received a great deal of criticism as to its overreliance on linearity, rationality and cognitivism in effecting perspective transformation. In this respect, researchers argue that in order a significant transformation to take place, it requires the involvement of the whole person, that is, all mind, body and spirit have to be attended to. Hence, transformative learning theories should be extended to include, besides cognitive, physical, affective and spiritual domains, ultimately imitating everyday life in which all four dimensions coexist and interact, governing all human action.

We strongly believe that when we come to teaching and learning, linear and fragmented approaches cannot account for the perplexity of the human being, consisting of mind, body and spirit, and therefore all three of them should be taken into account. Hence, we deem that further research under the holistic learning spectrum is required, in order to elucidate the obscure and complex processes of transformative learning.

\section{Acknowledgments}

The present study has not received any funding.

Part of the study has been presented at the 1st International Conference on Transformative Learning, held in Athens, Greece on June 27th-29th.

\section{References}

Adamson, C. W., \& Bailie, J. (2012). Education versus learning: Restorative practices in higher education. Journal of Transformative Learning, 10(3), 139-156. http://dx.doi.org/10.1177/1541344612463265

Bordo, S. R. (1987). The fight to objectivity. Albany, NY: State University of New York Press.

Boyd, R. D. (1989). Facilitating personal transformations in small groups: Part I. Small Group Behaviour, 20(4), 459-474. http://dx.doi.org/10.1177/104649648902000406

Boyd, R. D. (1991). Personal transformations in small groups: A Jungian perspective. New York: Routledge. http://dx.doi.org/10.4324/9780203359099

Brookfield, S. (1989). Developing critical thinkers. San Francisco, CA: Jossey-Bass.

Clark, M. C. (2005). Embodied learning. In L. English (Ed.), International Encyclopedia of Adult Education (pp. 210-213). London: Palgrave Macmillan.

Dencev, H., \& Collister, R. (2010). Authentic Ways of Knowing, Authentic Ways of Being: Nurturing a Professional Community of Learning and Praxis, Journal of Transformative Education, 8, 178,

Dewey, J. (1938). Experience and education. New York: Collier.

Dirkx, J. M. (2001). The power of feelings: Emotions, imagination, and the construction of meaning in adult learning. In S. B. Merriam (Ed.), The new update on adult learning theory: New Directions for Adult and Continuing Education, no 89 (pp. 63-72). San Francisco, CA: Jossey-Bass.

Dixon, R. A., \& Baltes, P. B. (1986). Towards Life-span research on the functions and pragmatics of intelligence. In R. J. Stenberg, \& R. K. Wagner (Eds.), Practical Intelligence (pp. 203-234). Cambridge University Press.

Freire, P. (1972.) Pedagogy of the oppressed. London: Penguin.

Gall, M. D., Borg, W. R., \& Gall, J. P. (1996). Educational research: An introduction. White Plains NY: Longman.

Habermas, J. (1970). Knowledge and human interests. Boston: Beacon Press.

Heshusious, L., \& Ballard, K. (1996). From positivism to interpretivism and beyond. New York: Teachers College Press.

Hillier, Y. (2005). Reflective teaching in further and adult education (2nd ed.). London: Continuum.

Howden, E. (2012). Outdoor experiential education: Learning through the body. New Directions for Adult and Continuing Education, 134, 43-52. http://dx.doi.org/10.1002/ace.20015

Kidd, J. R. (1973). Relentless Verity: Education for Being-Becoming-Belonging. Address delivered upon receiving the Syracuse University William Pearson Tolley Medal for Distinguished Leadership in Adult Education. New York: Syracuse University. 
Kohlberg, L. (1981). The philosophy of moral development: Moral stages and the idea of justice. New York: Harper and Row.

Kolb, D. A. (1984). Experiential Learning: Experience as a source of learning and development. Englewood Cliff, NJ: Prentice Hall.

Kramer, D. A. (2000). Wisdom as a classical source of human strength: Conceptualization and empirical enquiry. Journal of Social and Clinical Psychology, 19, 83-101. http://dx.doi.org/10.1521/jscp.2000.19.1.83

Lawrence, R. L., \& Cranton, P. (2009). What You See Depends Upon How You Look: A Photographic Journey of Transformative Learning. Journal of Transformative Education, 7(4), 312-331. http://dx.doi.org/10.1177/1541344610392378

Loevinger, J. (1976). Ego-development: Conceptions and theories. San Francisco, CA: Jossey-Bass.

Lovat, T., Clement, N., Dally, K., \& Toomey, R. (2010). Values education as holistic development for all sectors: Researching for effective pedagogy. Oxford Review of Education, 36(6), 713-729. http://dx.doi.org/10.1080/03054985.2010.501141

Merriam, S. B., \& Ntseane, G. (2008). Transformational learning in Botswana: How culture shapes the process. Adult Education Quarterly, 58, 1-16. http://dx.doi.org/10.1177/0741713608314087

Merriam, S. B. (2005). Adult learning. In L. M. English (Ed.), International Encyclopedia of Adult Education (pp. 42-48). London: Palgrave Macmillan.

Merriam, S. B., Caffarella, R. S., \& Baumgartner, L. M. (2007). Learning in adulthood: A comprehensive guide (3rd ed.). San Francisco, CA: Jossey-Bass.

Meyer, P. (2012). Embodied learning at work: Making the mind-set shift from workplace to playspace. New Directions for Adult and Continuing Education, 134, 25-32. http://dx.doi.org/10.1002/ace.20013

Mezirow, J. (1991). Transformative dimensions of adult learning. San Francisco, CA: Jossey-Bass.

Mezirow, J. (2000). Learning to think like an adult: Core concepts of transformation theory. In J. Mezirow, \& Associates (Eds.), Learning at transformation: Critical perspectives on theory in progress (pp. 3-33). San Francisco, CA: Jossey-Bass.

Michelon, E. (1998). Re-membering: The return of the body to experiential learning. Studies in Continuing Education, 20, 217-233. http://dx.doi.org/10.1080/0158037980200208

Moore, T. (2005). Educating for the soul. In J. P. Miller, S. Karsten, D. Denton, D. Orr, \& I. C. Kates (Eds.), Holistic learning and spirituality in education (pp. 9-16). Albany, NY: State University of New York Press.

Mulvihill, M. K. (2003). The catholic church in crisis: Will transformative leaning lead to social change through the uncovering of emotions? In C. A. Wiessmer, S. R. Meyer, N. L. Pfhal, \& P. G. Neaman (Eds.), Proceedings of the Fifth International Conference on Transformative Learning (pp 320-325) New York: Teachers' College, Columbia University.

Nitschke, P., \& Malvicini, P. (2013). Drawing toward Transformation and Action in a Forgotten Barrio: Cultivating a Learning and Planning Community. Journal of Transformative Education, 11(2), 127-144. http://dx.doi.org/10.1177/1541344613500218

Piaget, J. (1954). The construction of reality in the child. New York: Basic Books. http://dx.doi.org/10.1037/11168-000

Polanyi, M. (1969). Knowing and being. Chicago: University of Chicago Press.

Pugh, K. J. (2011). Transformative Experience: An Integrative Construct in the Spirit of Deweyan Pragmatism. Educational Psychologist, 46(2), 107-121. http://dx.doi.org/10.1080/00461520.2011.558817

Riegel, K. F. (1973). Dialectic operations: The final period of cognitive development. Human Development, 16, 346-370. http://dx.doi.org/10.1159/000271287

Schön, D. A. (1983). The reflective practitioner: How professionals think in action. New York: Basic Books.

Shor, I. (1992). Empowering education: Critical teaching for social change. Chicago: University of Chicago Press.

Sloan, D. (2005). Education and the modern assault on being human: Nurturing body, soul, and spirit. In J. P. Miller, S. Karsten, D. Deston, D. Orr, \& I. C. Kates (Eds.), Holistic Learnig and spirituality in education (pp. 27-46). Albany, NY: State University of New York Press. 
Taggart, G. (2001). Nurturing Spirituality: A rationale for holistic education. International Journal of Children's Spirituality, 6(3), 325-339. http://dx.doi.org/10.1080/13644360120100496

Taylor, E. W. (2000). Analyzing research on transformative learning theory. In J. Mezirow, \& Associates. (Eds.), Learning as transformation: Critical perspectives on a theory in progress (pp. 285-328). San Francisco, CA: Jossey-Bass.

Taylor, K., Marienau, C., \& Fiddler, M. (2000). Developing adult learners. San Francisco, CA: Jossey-Bass.

Tisdell, E. J. (2003). Exploring spirituality and culture in adult and higher education. San Francisco, CA: Jossey-Bass.

Wang, M., \& Yorks, L. (2012). Behind the Resume: A Holistic Approach to Deepen Self-Awareness. Journal of Transformative Education, 10(3), 157-176. http://dx.doi.org/10.1177/1541344612463439

Yorks, L., \& Marsick, V. J. (2000). Organizaional learning and transformation. In J. Mezirow, \& Associates. (Eds.), Learning as transformation: Critical perspectives on a theory in progress (pp. 253-281). San Francisco, CA: Jossey-Bass.

\section{Copyrights}

Copyright for this article is retained by the author(s), with first publication rights granted to the journal.

This is an open-access article distributed under the terms and conditions of the Creative Commons Attribution license (http://creativecommons.org/licenses/by/3.0/). 